

\title{
Ética e equilíbrio entre texto e imagem
}

\author{
Simonetta Persichetti*
}

Uma das entrevistas desta edição é com o jornalista Hélio Campos Mello, diretor de redação da revista Brasileiros. Forjado na melhor escola do jornalismo - na qual ética não é apenas uma palavra no dicionário começou como fotógrafo nos anos 70, no Jornal da Tarde. Foi nessa escola que Hélio aprendeu que fotojornalista é, antes de tudo, um jornalista. Como fotógrafo passou por importantes redações, como a do jornal Ultima Hora e a da revista Veja. Em 1976, a convite de Mino Carta, participou da fundação da revista IstoÉ. Exerceu o cargo de editor de fotografia até o início dos anos 90, quando saiu para comandar aAgência Estado. Foi no Estadão que mais trabalhou para o reconhecimento do fotojornalista, fazendo a fotografia ser vista em pé de igualdade com o texto, paridade que mantém até hoje em sua revista, a Brasileiros.

Além de buscar o equilíbrio entre texto e imagem, Hélio procura resgatar o bom jornalismo em amplas reportagens que não apenas apresentam um assunto, mas procuram aprofundar e desvendar histórias que - como diz o lema de sua publicação - valem a pena ser contadas.

Esta entrevista foi concedida em meio a um fechamento de edição, no apagar das luzes de 2009. Mesmo assim, ele se dispôs a dividir com os leitores da Discursos Fotográficos seus pensamentos sobre fotografia e jornalismo. Não é sempre que um fotógrafo se torna diretor de redação, mas, acima de tudo, Hélio Campos Mello é um jornalista, como poucos se encontram hoje.

\footnotetext{
*Jornalista e crítica de fotografia. Doutora em Psicologia Social pela Pontifícia Universidade Católica de São Paulo. Professora do Mestrado em Comunicação da Universidade Estadual de Londrina. Escreve sobre fotografia para $O$ Estado de $S$. Paulo e coordena a pesquisa e publicação da Coleção Senac de Fotografia. Autora dos livros Imagens da fotografia brasileira I e II, publicados pela Estação Liberdade e Senac.
} 


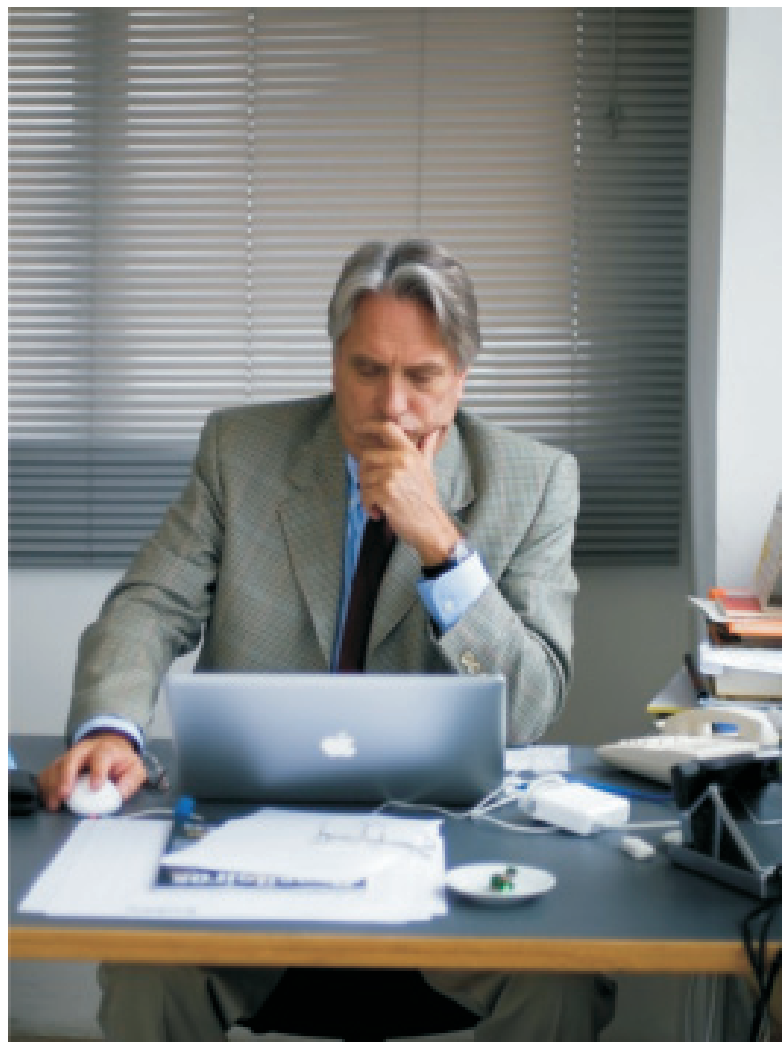

Hélio Campos Mello

Fotografia: Luiza Sigulem

\section{Entrevista}

Simonetta - Vamos tentar definir o que é fotojornalismo?

Hélio - A meu ver fotojornalismo, hoje, é o produto testemunhal da observação de um evento. O fotojornalismo é exercido por um indivíduo, por um jornalista, especializado na produção de imagens, na produção de fotografias. A forma desse produto é uma ou mais fotografias elaboradas segundo uma estética subjetiva e autoral. 
Simonetta - Podemos dizer que a estética do fotojornalismo se alterou com o digital ou, talvez melhor dizendo, na contemporaneidade?

Hélio - O digital facilita e agiliza a transformação da observação de determinado evento em imagem ou em imagens. Da mesma maneira que os filmes e as câmeras de $35 \mathrm{~mm}$ facilitaram no passado. Idem para os motor-drives nessas câmeras. O que eu quero dizer é que a tecnologia - de hoje, de ontem e de amanhã - importa pouco perto do fundamental que é o poder de observação do individuo. Portanto, a importância não está no digital e sim no poder de observação do fotojornalista e em suas implicações. Quanto melhor seu nível de informação, de atenção, quanto melhor sua agilidade de análise e de raciocínio, sua previsão do desenrolar do evento para melhor se posicionar para registrá-lo, quanto melhor seu arcabouço ético, seu respeito às pessoas e ao entorno e seu bom humor, melhor será a qualidade final de seu trabalho. $O$ digital está a serviço de tudo isso.

Simonetta - Uma das grandes críticas ao jornalismo de hoje é de que a estética está muito próxima da publicidade, ou seja, mais preocupada com a arte e menos com jornalismo. Como você vê isso?

Hélio - Da mesma maneira que no passado. A atração e embevecimento pelas aberrações óticas produzidas, por exemplo, pelas lentes fish eye, ou pelas grande- angulares mal usadas, demonstravam um produto final de baixa qualidade e revelavam uma melancólica pobreza de observação, também o embevecimento com a tecnologia digital e seu potencial de alteração da realidade demonstram uma distração, na melhor das hipóteses, ou uma deterioração, um emburrecimento em relação à essência do fotojornalismo. Fotojornalismo é testemunhar, observar, analisar e registrar a realidade. Acho que, dito isso, hoje, como sempre, se faz bom fotojornalismo e mal fotojornalismo. Hoje há, a meu ver, um crescimento da burrice e isso impacta na qualidade dos julgamentos. Há melhores trabalhos relegados, desprezados e mais lixo incensado, valorizado. Principalmente lixo embalado em marketing pessoal e/ou pixels cintilantes. 
Simonetta - Discute-se muito hoje em dia a manipulação de imagens e o uso do photoshop. Como você avalia estas discussões? O que é licito o que não é?

Hélio - Em relação ao photoshop penso o mesmo: é uma tremenda ferramenta e como tal deve ser usada. Nos antigos laboratórios com cheiro de acido acético era bastante válido reforçar as altas luzes de um negativo de uma copia fotográfica em papel com o uso de ferricianeto (ou ferricianureto) de potássio. Usar o ferricianeto para tirar alguém da fotografia, não. O mesmo vale para o photoshop: é o limite entre que pode e o que não pode, mas quem determina é o fotojornalista.

Simonetta - Você ficou algum tempo sem fotografar profissionalmente, atividade a qual retornou mais assiduamente nos últimos dois, três anos. Você percebeu transformações do seu olhar? Foi preciso voltar a treinar, quer dizer, aprender a (re)enxergar?

Hélio - Vivo um agradável processo de retomar o "fotografar". Estou fazendo uma revista com um ótimo espaço para fotografias, estou cheio de planos, cheio de projetos, estou pesquisando equipamento para comprar. Tem uma frase muito legal sobre tênis que é um esporte que eu gosto: quando você é jovem, você consegue chegar com muita facilidade e rapidez à rede, mas quando chega lá você não sabe o que fazer. Quando você não é mais jovem você sabe o que fazer, mas não consegue chegar à rede com tanta facilidade. Apesar da implacabilidade embutida na equação acho muito mais importante saber fazer. Chegar, a gente chega; não tão rápido, mas chega. Ou seja, posso demorar para fotografar, me embananar com técnica que ainda não domino, mas o meu poder de observação está cada vez melhor. E isso é o que importa.

Simonetta - Você percebe, hoje, formas diferenciadas ao fotografar jornalisticamente. Ou o cerne do fotojornalismo não se alterou? Quero dizer a forma de trazer ou contar notícias.

Hélio - Hoje você tem novos suportes, como a internet, que tem um formato e uma linguagem diferente. Eu acho que isto tem que 
estar na sua cabeça na hora de fotografar. Mas, ao mesmo tempo, isso não pode mudar nem interferir na maneira de você observar. Acho que a sua produção fotográfica, ou seja, a transformação da sua observação em imagens eficientes, em fotojornalismo eficiente deve agregar as novas mídias. Mas isso, de novo, não pode sacrificar o seu patrimônio que é o seu poder de observar com eficiência e inteligência.

Simonetta - Como fotojornalista qual a imagem que você fez e pensou: "consegui!"?

Hélio - Já fiz várias e também não fiz outras tantas. Das que eu fiz, lembro de uma careta anunciada do Bush para o Collor que consegui prever e registrar quando aconteceu. Outra foi um retrato de um banqueiro furioso soltando fumaça pelas ventas, gesto também anunciado ao acender o cachimbo, que consegui finalmente registrar com bastante eficiência. Também há várias que não fiz. Não fiz um gol do Basílio na vitória do Corinthians contra a Ponte Preta, e não porque sou são-paulino. Eu perdi a fotografia porque estava trocando de lente na hora errada. Não fiz as fotografias da minha prisão no Iraque porque me confiscaram as câmeras, e muitas outras que deixei de fazer.

Simonetta - No mesmo sentido, alguma vez, você baixou a câmara e pensou: "não vou fazer"? Quando?

Hélio - Deixei de fazer várias. E algumas continuarei não fazendo. Deixei de fotografar, por exemplo, uma mãe chorando à beira da cama de seu filho, mortalmente ferido num acidente de trem.

Simonetta - Como equilibrar texto e imagem?

Hélio - Não é fácil. Repórter e fotojornalista têm que se entender. E isso é muito difícil. É uma luta. Uma guerra. Uma disputa de poder. É uma luta a ser lutada. Mas tem hora que cansa. Por isso que é bom fotojornalista saber escrever. 
Simonetta - Como foi sua passagem do analógico para o digital? Mudou a visualidade ou para você é apenas uma mudança de suporte?

Hélio - Ainda estou mudando. Estou em plena transição. Ainda tenho uma Hasselblad x-pan movida a filmes e uma Canon g-10 e uma Nikon digitais. Ainda não estou nem satisfeito, nem seguro. Estou em transição.

Simonetta - De forma "visionária", quando muitos falam no fim do jornalismo, você resolveu montar uma revista. Por quê?

Hélio - A vertiginosa velocidade do trânsito de informação, hoje, muda radicalmente a prioridade dos meios. Perdem os jornais e as revistas semanais. Ganham a internet e as revistas mensais de qualidade. É esse caminho que estou encarando. Tenho as duas coisas: a internet e a revista Brasileiros. E há um bom espaço, em ambos, para o fotojornalismo. Recomendo, com a maior desfaçatez, reconheço, a leitura da revista impressa e também do site www.revistabrasileiros.com.br, onde há um belo espaço para fotojornalismo.

Simonetta - Claro que não dá para reviver os tempos das grandes revistas ilustradas. Como se manter ou furar um esquema de jornalismo espetáculo, mais voltado para o entretenimento do que para as notícias?

Hélio-A revista mensal bem feita recupera o fetiche da leitura. É como entrar em uma papelaria e sentir o cheiro de papel e de grafite. Uma semanal, que se compra no sábado, hoje não dura mais do que três dias. Uma mensal boa, bem feita, com boa pauta, bom tratamento gráfico, qualidade de textos e de fotografias, tem uma duração bem maior, seja na sala, no banheiro ou no criado mudo.

Simonetta - Em termos fotográficos, como fazer para que a imagem não perca sua eficiência?

Hélio - Há que se usar com parcimônia. É como nóz moscada. É bom na medida certa. Caso contrário estraga o prato. Banaliza. Enjoa. 
Simonetta - Você tem uma frase que considero fundamental: "o fotojornalismo muitas vezes publica o óbvio eficiente". Como fugir disso sem perder a eficiência jornalística?

Hélio - Observando com interesse, com respeito, com vagar, com ética. É evidente que não se faz fotografia boa toda hora. Depende do seu momento, da sua cabeça, do seu espírito, de várias coisas.

Simonetta-Qual a importância da formação acadêmica para um fotojornalista?

Hélio - Toda a formação/informação é fundamental. Quanto mais, mais bem vinda. Eu, por exemplo, ainda tenho a esperança, ou a fantasia, de fazer uma faculdade (História, de preferência), mesmo que tarde.

Simonetta-Nadar, famoso retratista do século XIX, dizia: "Técnica fotográfica se aprende em 15 minutos. Para tornar-se fotógrafo é preciso uma vida inteira." Comente.

Hélio - Concordo plenamente. E acho que já comentei isso, quando citei o exemplo do tênis.

Simonetta - Hoje, quais imagens jornalísticas te agradam e quais desagradam?

Hélio-Estética, equilíbrio gráfico, emoção - tristeza ou bom humor - me chamam a atenção.

Simonetta - Você tem ídolos no fotojornalismo? Quem? Por quê?

Hélio - Tenho respeito. Respeito muito uma fotógrafa jovem que se chama Luiza Sigulem. Ela trabalha comigo na revista Brasileiros. Começou como estagiária e agarrou uma chance com unhas, dentes e muita criatividade. Respeito o seu crescimento.

Simonetta-Você consegue vislumbrar ou tentar falar sobre o futuro do jornalismo e, portanto, do fotojornalismo?

Hélio-Acho o presente suficientemente intenso e rico em mudanças de rumo e de rotas. Não consigo espaço para pensar no futuro. 